\title{
Teaching Experience and Syllabus on High Performance Computing
}

\author{
Hong HE ${ }^{1, a}$, Shengzhong YUAN ${ }^{2, b, ~ * ~}$ \\ ${ }^{1}$ School of Mechanical, Electrical \& Information Engineering, \\ ${ }^{2}$ Network and information management center\}, Shandong University, Weihai, 264209, China \\ aemail: hehong@sdu.edu.cn, bemail: ysz@sdu.edu.cn, *Corresponding author
}

Keywords: Higher Education, Computer Science and Technology, High Performance Computing, Parallel Computing, Syllabus, Teaching Experience, Curriculum Content and Hours

\begin{abstract}
Due to the lag of the curriculum systems and the difficulties in parallel programming, there are few national universities to provide high performance computing (HPC) or parallel computing courses for undergraduate students. With the arrival of the era of research with big data, many universities have set up their own HPC laboratory, the conditions of teaching HPC related curriculums for undergraduate students are ready. In order to train professional talents who can apply and use HPC clusters, we design a HPC course system for computer science and technology majors and graduate students. A set of HPC courses for non-computer majors is also proposed. The proposed HPC curriculum content and the number of hours are the result of teaching and experiment by ourselves.
\end{abstract}

\section{Introduction}

With the arrival of the era of big data, high performance computing (HPC) and cloud computing based on HPC have become the most important information infrastructure. More and more powerful computer clusters provide people with more and more powerful abilities to solve problems in scientific research and production, they also require people to have more and more powerful capabilities of programming. Enterprises have to handle big data using HPC or cloud resources. The demand for HPC professional talents is increasing.

Almost all of the Chinese universities in the field of science and engineering have the major of computer science and technology. Among them, many colleges and universities due to the needs of scientific research has invested heavily in the construction of HPC Center laboratory. But only about twenty of them provide HPC curriculums to students. Obviously it is a significant waste of university resources.

According to the investigation, some high level Chinese universities, such as Peking University, Tsinghua University and University of Science and Technology of China (USTC) have been attaching great importance to HPC course system. In the new training programs (Ver. 2016) of Peking University, the major of computer (including science direction and technology direction), the major of software engineering, and the major of data science and big data have set in two HPC corresponding curriculums which are "Principles of parallel programming" (in the second grade, second semester, 2 credits) and "Introduction to parallel and distributed computing" (in the third grade, second semester, 3 credits). These two curriculums in succession enable students with basic $\mathrm{C} / \mathrm{C}++$ programming ability work using HPC clusters. Tsinghua University, USTC, Sun Yat-sen University, Huazhong University of Science and Technology, and Dalian University of Technology have trained their students to participate in the world university supercomputer contest and get an excellent mark [1].

Taking into account the urgent requirements of training HPC talents, referring to the existing university training plans and teaching experience, we will give a set of training programs to train HPC talents in universities. If there is a HPC central laboratory or HPC practice base in the university, the following training programs may be used. This program is designed and experienced in the HPC Center laboratory in Shandong University, Weihai where all of the main cluster devices are products 
of INSPUR. The references are suggested to adjust corresponding contents based on their own experiments and practice conditions when needed. We assume that all of the students have learned the $\mathrm{C} / \mathrm{C}++$ and have the appropriate programming basis.

The following three parts are three different syllabus which are syllabus for undergraduate and graduate students in major of computer science and technology, syllabus for students in computer interdisciplinary majors who will need to use HPC cluster, and syllabus for students in non-computer majors. Then we show a list of textbooks and reference books. The last part is a conclusion.

\section{Syllabus for Undergraduate and Graduate Students in the Major of Computer Science and Technology}

According to the teaching experiences, we propose a curriculum named "Introduction to HPC" and try to describe the outline of teaching and experiment. The outline is the most important of the three sets of syllabus which is suitable for the second semester in Grade 2 . We use 48 lessons to teach the main content and the students finish experiments in 16 hours. Total credits are 3.5. It is easy to be selected as an elective course in the current training program for students to choose. This will have an immediate effect for updating the existed training plan. The precursor courses are $\mathrm{C} / \mathrm{C}++$ and LINUX. The basic contents and hour assignment are as follows.

Chapter 1 overview of HPC systems (6 hours)

1.1 Definition and development of HPC systems

1.2 Introduce an instance of constructing a HPC center lab

1.3 Introduction to domestic brand: INSPUR and SUGON

1.4 HPC application examples and characteristics

1.5 From high performance to high efficiency

\section{Homework}

1-1 Search a typical HPC system in the main HPC application areas, study its structure and performance. Analyze the special structural characteristics of the HPC system in order to complete the design objectives. Some students will be chosen to represent their homework in the class.

1-2 Apply for a HPC account with your login ID on the campus network. Modify your password after obtaining the approval.

1-3 Visit the HPC center Lab and listen to the technical staff.

Chapter 2 Introduction to parallel computing (10 hours)

2.1 Principles of parallel computing and parallel computer

2.2 Parallel computer system interconnection and system structure

2.3 Contemporary parallel computer systems: SMP, MPP and COW

2.4 Parallel computing models

2.5 The performance evaluation of parallel computer systems

2.6 Review of LINUX command set

Homework

2-1 Research on the development of various parallel architectures and computational models

2-2 What are the differences between HPC and cloud computing?

2-3 Practice using the Linux commands

2-4 Visit a cloud computing center and listen to the technical staff

Chapter 3 Method of developing parallel applications on cluster (24 hours)

3.1 Building a heterogeneous parallel development environment

3.2 Development of heterogeneous parallel software 
3.3 The basis of parallel algorithm design

3.4 Programming basis of Open MP and MPI

3.5 Architecture of MIC hardware and software

3.6 MIC programming

3.7 Architecture of GPU hardware and software

3.8 GPU programming

3.9 Two examples: complete solution process

Homework

3-1 How to pick out parts that can be parallelized in a serial program?

3-2 When you choose MIC? When you choose GPU?

3-3 Understanding SCIF programming and MIC software debugging.

Chapter 4 Development method of parallel application software on a cluster (4 hours)

4.1 Traditional high performance evaluation system

4.2 HPC application evaluation systems of INSPUR and SUGON

4.3 Analysis of HPC application instances features

Homework

4-1 evaluating your HPC center Lab.

Chapter 5 Case analysis (4 hours)

5.1 HPC application development strategy and case on MIC platform

5.2 The complete solution of a problem from ASC contests

Homework

5-1 Researches on ASC contents topics of the last three times.

The syllabus corresponding experimental outline is as Table 1.

Table 1. Experiments outline

\begin{tabular}{|c|l|c|l|}
\hline No. & \multicolumn{1}{|c|}{ Experimental contents } & Hours & \multicolumn{1}{|c|}{ Experimental environments } \\
\hline 1 & Linux commands practices. & 3 & $\begin{array}{l}\text { PC terminals and INSPUR TS10000 high performance } \\
\text { servers. }\end{array}$ \\
\hline 2 & Open MP \& MPI programming & 3 & $\begin{array}{l}\text { PC terminals and INSPUR TS10000 high performance } \\
\text { servers. }\end{array}$ \\
\hline 3 & $\begin{array}{l}\text { CPU+MIC programming: Calculate value of } \\
\text { PI. }\end{array}$ & 3 & $\begin{array}{l}\text { PC terminals and INSPUR TS10000 high performance } \\
\text { servers. }\end{array}$ \\
\hline 4 & CPU+GPU programming: Render a picture. & 3 & $\begin{array}{l}\text { PC terminals and INSPUR TS10000 high performance } \\
\text { servers. }\end{array}$ \\
\hline 5 & Solve an ASC contest problem & 4 & $\begin{array}{l}\text { PC terminals and INSPUR TS10000 high performance } \\
\text { servers. }\end{array}$ \\
\hline
\end{tabular}

\section{Syllabus for Students in Computer Interdisciplinary Majors}

Students in computer interdisciplinary majors such as Big Data, Financial, Statistical, Digital Media and Space Science, have a lot of opportunities to deal with big data with the techniques of HPC or cloud computing. Most of them have learned more or less $\mathrm{C} / \mathrm{C}++$ programming. But few of them are able to skillfully use LINUX as an operating system. So we have to spend more time talking about LINUX at first. For the students who have never learn HPC related courses, they may learn in 32 hours. Following is a modified syllabus. 
Chapter 2 Introduction to parallel computing (10 hours)

Chapter 3 Method of developing parallel applications on cluster (14 hours)

Chapter 4 Development method of parallel application software on a cluster (4 hours)

Chapter 5 Case analysis (2 hours)

Students who take this curriculum don't need to do experiments. If conditions permit, visit to the HPC center Lab and visit to a cloud computing center are necessary. Arrange technical staff to explain the system structures and network interconnection as detailed as possible when visiting, and conduct on-site discussions with graduate students. Doing so can give them an intuitive feel for HPC. They already have basic knowledge when they need to use a HPC cluster.

If the syllabus is used to teach graduate students of science and engineering, you may increase the content of big data algorithms and examples [5]. Please add 32 hours of experiment items which will be finished by the graduate students themselves. It is better if they are able to experiment with their own research directions or items. Like the undergraduate students, we do not have to arrange a special laboratory, teachers can understand the situation of students' jobs through the management software and the experiment guidance is by WeChat or QQ group online Q \& A.

\section{Syllabus for Students in Non-computer Related Majors}

In the majors of non-computer related, students are not the same, and the requirements for computer application ability are also different. So we propose the curriculum "Introduction to HPC" as an elective course of 16 hours ( 0.5 credits) to introduce HPC. The syllabus is as follows.

Chapter 1 overview of HPC systems (4 hours)

Chapter 2 Introduction to parallel computing (4 hours)

Chapter 3 Method of developing parallel applications on cluster (6 hours)

Chapter 4 Development method of parallel application software on a cluster (2 hours)

In the first chapter, according to the professional situation of students, we demonstrate the application of HPC as much as possible in the fields of professional and similar fields. We also organize students to show domestic and foreign HPC application progress in their own professional fields in the class.

Students who take this curriculum don't need to do experiments. If conditions permit, visit to the HPC center Lab and visit to a cloud computing center are necessary. They know the HPC cluster when they see. Arrange technical staff to explain the system structures and network interconnection when visiting, and show them the typical application to strengthen impressions.

All of above are to deepen the students' impression of HPC which is a powerful tool to solve problems. Like Internet, all students should know new IT Technology. Nobody knows when and where he'll be able to use it.

\section{About Textbooks and References}

Students generally do not need to buy textbooks for elective courses. Professors can recommend three main reference books to students:

(1) CHEN Guoliang, Parallel Computing: Architecture, Algorithm and Programming, Published by Higher Education Press. ISBN 978-7-0400-7739-1, Oct, 1999.

(2) WANG Endong, ZHANG Qing, SHEN Bo, ZHANG Guangyong, LU Xiaowei, WU Qing, WANG Yajuan, HPC Programming Guide, ISBN 978-7-5170-0338-0. www.waterpub.com.cn, Nov, 2012.

(3) WANG Endong, etc. High Performance Computer System: Design and Application. Published by Science Press. ISBN 978-7-03-040281-3, Apr, 2014. 
(4)WANG Hongzhi, Big Data Algorithms, Published by China Machine Press. ISBN 978-7-111-50849-6, Jan, 2016.

The references [2] \& [4] are usually used as main textbooks in the major of computer, [3] is helpful for experiments.

\section{Conclusions}

We have proposed three programs about how to set HPC courses in the universities. According to the actual situation of the University, such as the experimental environment, students and teachers conditions, we can set up the HPC or parallel computing related courses with different credits or various curriculum names independently for several majors [6, 7]. But the main object is students in the major of computer [8]. Other students can learn about HPC as well as Internet. For the same HPC curriculum, teaching students as scientific type, engineering type or application type is another good idea [9].

For the undergraduate students in the major of computer science and technology, the HPC related courses (2 3 curriculums) can form a new professional HPC direction. If students can learn HPC courses in the second year, some of the best may be selected to participate in the enterprise training in the first semester of Grade 3 and then enter for the ASC contest in the next spring. According to the ASC contests schedule and personnel requirements, students will not have enough time to participate in the contest if they have HPC classes in Grade 3.

\section{Acknowledgement}

This work is financially supported by Shandong province key teaching research project in the year 2015 (Researches on training mode of innovative high performance computing talents). Thanks for the support of Shandong University, Weihai. Specially thanks for the support of INSPUR. The HPC engineers of INSPUR have given us good advice and help in the teaching, experiment as well as practice training contents.

\section{References}

[1] http://www.it168.com/redian/ASC16/

[2] CHEN Guoliang, Parallel Computing: Architecture, Algorithm and Programming, Published by Higher Education Press. ISBN 978-7-0400-7739-1, Oct, 1999.

[3] WANG Endong, ZHANG Qing, SHEN Bo, ZHANG Guangyong, LU Xiaowei, WU Qing, WANG Yajuan, HPC Programming Guide, ISBN 978-7-5170-0338-0. www.waterpub.com.cn, Nov, 2012.

[4] WANG Endong, etc. High Performance Computer System: Design and Application. Published by Science Press. ISBN 978-7-03-040281-3, Apr, 2014.

[5] WANG Hongzhi, Big Data Algorithms, Published by China Machine Press. ISBN 978-7-111-50849-6, Jan, 2016.

[6] http://www.pku.edu.cn/education/kcsz/bkskcsz/index, Mar, 2017

[7] http://www.teach.ustc.edu.cn/education/241.html, Mar, 2017

[8] http://www.tsinghua.edu.cn/publish/newthu/newthu_cnt/education, Mar, 2017

[9] Steering Committee on computer science and technology, Ministry of Education, The implementation of the core courses of computer science and technology in Colleges and Universities, July, 2009. http://www.hep.com.cn. 